\title{
Association Between Early Administration of Norepinephrine in Septic Shock and Survival
}

This article was published in the following Dove Press journal: Open Access Emergency Medicine

\author{
Mohammed S Alshahrani (iD) \\ Rawan Alatigue ${ }^{2}$ \\ 'Emergency and Critical Care \\ Departments, King Fahd Hospital of the \\ University, Imam Abdulrahman Bin Faisal \\ University, Dammam, Kingdom of Saudi \\ Arabia; ${ }^{2}$ Department of Emergency \\ Medicine, King Fahd Specialist Hospital, \\ Dammam, Kingdom of Saudi Arabia
}

Introduction: Septic shock still carries a high mortality rate despite all advances in emergency and critical care practices. Early interventions have been proven in many aspects to improve outcome. However, early administration of vasopressors namely norepinephrine in septic shock is still controversial.

Objective: To identify the association between early norepinephrine administration and mortality in septic shock patients.

Methods: A retrospective review of a prospectively collected ICU data for septic shock patients in medical and surgical intensive care units for one year period was carried out. Case definition was based on sepsis 3 definitions. Data included patients' characteristics of demographics, admission diagnosis, APACHE II score, physiological data (including vital signs and laboratory values). The primary outcome was 28 days of mortality.

Results: A total of 243 patients identified during the study period, 132 (54.3\%) were male. The mean age was found to be $58.9 \pm 20.3$. The overall rate of 28 days mortality was 87 (47.5\%). Norepinephrine was started for $68.9 \%$ of the patients in ICU, the rest were started in the emergency department. The highest survival rates were among patients who received norepinephrine within first hour (58.1\%) and second (51.5\%). A binary logistic regression analysis has been performed to adjust for possible confounders. It was revealed that being intubated and mechanically ventilated or having higher APACHE II score were strongly associated with non-survival rates $(\mathrm{OR}=7.049$, $\mathrm{p}-0.002),(\mathrm{OR}=1.124, \mathrm{p}-<0.001)$ respectively. Conclusion: Our results showed that septic shock patients who had early administration of norepinephrine had a higher survival rate. Intubation and invasive ventilation and higher APACHE II score associated with higher none survival rate.

Keywords: sepsis, septic shock, antibacterial agents

\section{Introduction}

Septic shock and sepsis are two the major causes of presentation in the Emergency Department (ED) and the Intensive Care Unit (ICU). Incidents of sepsis have been on a rise and continue to be a leading cause of morbidity, mortality and growing healthcare cost during its treatment and management. ${ }^{1-4}$ The public health burden linked to sepsis is increasingly growing. An effective approach to the management and treatment of sepsis is through early detection. ${ }^{1,3}$ Surviving Sepsis Campaign (SSC) guidelines offer health providers with a set of recommendations that guide their management including early recognition, monitoring, administration of fluid and vasopressors therapies. ${ }^{2,3}$ Previous studies on treatment interventions for sepsis and septic shock have indicated high efficacy in early norepinephrine administration for improvement of patient outcomes in acute cases. ${ }^{6}$ A meta-analysis did not
Correspondence: Mohammed S Alshahran Emergency and Critical Care Departments, King Fahd Hospital of the University, Imam Abdulrahman Bin Faisal University,

Dammam, Kingdom of Saudi Arabia

Email msshahrani@iau.edu.sa 
indicate any improvement after norepinephrine administration in response to severe sepsis and septic shock 1 hour of shock identification and 3 hours of ED triage. ${ }^{7}$ Therefore, the inconsistencies are associated with variations in the study population, study design and definition of septic shock.

A 2010 study identified effectiveness in norepinephrine administration for the early treatment of patients with severe sepsis and septic shock who were admitted to the ICU facility. ${ }^{9}$ Recent studies have identified that a better understanding of the disease and treatment interventions could significantly lower the mortality for patients with sepsis and septic shock. ${ }^{12,13}$ Univariate regression performed in some studies to ascertain the effect of survival rate among selected clinical parameters. ${ }^{8,14,15}$ To ascertain the effectiveness of norepinephrine timing in the treatment of sepsis and septic shock is important based on quantitative determination of whether or not early norepinephrine administration could improve the outcomes for septic shock patients. ${ }^{2,5}$ The purpose of this study is evaluating whether the time to norepinephrine administration is linked to hospital mortality for a patient with sepsis and septic shock in the emergency department using univariate regression analysis to ascertain the effect of survival rate among selected clinical parameters.

\section{Materials and Methods Design and Participants}

The study involved a retrospective review of a prospectively collected ICU data. It is a single-center involving data on septic shock patients in both medical and surgical intensive care units for one year. The data collected involved both Saudi and non-Saudi nationalities comprising male and female sample aged from 15 years to 104 years old. A total sample of 243 patients was considered who comprised of male and female patients. The data from patients who were under the category of do not attempt resuscitation were not considered in the prospective observational study. The detailed registry description for the patients was reviewed to collect sufficient data on septic shock patients under different intensive care units in the Kingdom of Saudi Arabia hospitals. The institutional review board for each ICU provided the approvals to collect data and informed consent was sought before the collection of data to meet the ethical thresholds. The study followed the ethical standards of the institutional and national research committees and the Helsinki
Declaration. Ethical approval for this study was obtained from the Institutional Review Board of Imam Abdulrahman Bin Faisal University.

\section{Definitions and Outcome}

The case definitions were founded on the sepsis 3 definitions where data included patient demographic characteristics. Additionally, the other type of data collected included admission diagnosis, physiological data that included the vital signs and values from laboratory data, and APATCHII score (considers acute physiology score + chronic health points + age points. The minimum score is usually 0 and the maximum score is 71 . High score is linked to high risk of hospital death). The primary outcome was 28 days of mortality. Mann-Whitney U-test was used for continuous data while Chi-square test compared the categorical data. The multivariate regression analysis was used conducted in calculating the likelihood ratio between dependent variables and independent factors.

\section{Statistical Analysis}

The data analyses were performed using Statistical Packages for Social Sciences (SPSS) version 20, Armonk, NY: IBM Corp. Statistical values were presented as numbers and percentages for all categorical variables while the mean \pm standard deviation was used to presents all numerical variables. The comparison of categorical data had been conducted using chi-square test while the comparison of continuous data had been calculated using Mann Whitney $U$ test for non-parametric whereas independent $t$-test for the parametric test. The univariate regression analysis has been conducted as well to calculate the likelihood ratio between the dependent variable against independent factors where the odds ratio, as well as 95\% confidence interval, were also being reported. A $\mathrm{p}$-value of $\mathrm{p} \leq 0.05$ deemed as the significant level for all statistical tests. Normality of data was calculated using the Shapiro-Wilk test, $\mathrm{p}-<0.05$ was considered non-parametric.

\section{Results}

\section{Participant Characteristics}

This study includes 243 patients. Age range was from 15 to 104 years old. Of the 243 patients, $54.3 \%$ of them were males and $45.7 \%$ were females. Saudis dominated the nonSaudis $(78.7 \%$ vs $21.3 \%)$. The rate of the 28 -day survival was $65.5 \%$ while non-survival was $34.5 \%$. First 
Table I Description of Socio-Demographic Variables and Patient Outcome

\begin{tabular}{|c|c|}
\hline Study Variables & $\begin{array}{l}N(\%) \\
(n=243)\end{array}$ \\
\hline $\begin{array}{l}\text { Nationality } \\
\text { - Saudi } \\
\text { - Non-Saudi }\end{array}$ & $\begin{array}{l}192(79.0 \%) \\
51(21.0 \%)\end{array}$ \\
\hline $\begin{array}{l}\text { Gender } \\
\text { - Male } \\
\text { - Female }\end{array}$ & $\begin{array}{l}\text { I } 32 \text { (54.3\%) } \\
\text { I I I (45.7\%) }\end{array}$ \\
\hline $\begin{array}{l}28 \text { Days Survival rate * } \\
\text { - Survivor } \\
\text { - Non-Survivor }\end{array}$ & $\begin{array}{l}129(65.5 \%) \\
68(34.5 \%)\end{array}$ \\
\hline $\begin{array}{l}\text { Department where Ist Norepinephrine was given } \\
\text { - ER } \\
\text { - ICU }\end{array}$ & $\begin{array}{l}72(29.6 \%) \\
|7|(70.4 \%)\end{array}$ \\
\hline & Mean \pm SD \\
\hline Age in years & $59.8 \pm 20.4$ \\
\hline Time of Norepinephrine administration $(\mathrm{h})$ & I. \pm 02.0 \\
\hline
\end{tabular}

Note: $* 46$ cases are missing and were excluded from the analysis. Abbreviation: mean $\pm S D$, mean and standard deviation.

Norepinephrine was given at ICU (70.4\%). The mean time of Norepinephrine administration was 1.8 (SD 2.0) (Table 1).

\section{Characteristics of Patients Before Admission to ICU}

The characteristics of patients before ICU admission have been further discussed in Table 2. The most common diagnosis infection was sepsis (39.1\%), followed by pneumonia (14.4\%) and the least of them was urosepsis (7.8\%). Nearly all of them were having normal body temperature $(91.0 \%)$ whereas more than half of them were intubated patients $(58.1 \%)$. The mean MAP of the patients before ICU admission was 82.2 (SD 18.9) while the mean heart rate reading was 96.1 (SD 23.3) and the mean respiratory rate was 22.2 (SD 4.4) (Table 2).

\section{Mortality Rate After Initial Norepinephrine Administration}

Figure 1 presented the mortality rate of patients whose initial norepinephrine administration was within the indicated time interval. It was revealed that 3-3.99 hours was the highest mortality rates $(50 \%)$, followed by $2-2.99$ $(42.9 \%)$ and 4 hours or more $(40 \%)$. On the other hand,
Table 2 Characteristics of Patients Before Admission to ICU

\begin{tabular}{|l|l|}
\hline Characteristics & $\begin{array}{l}\text { N (\%) } \\
\text { (n=243) }\end{array}$ \\
\hline $\begin{array}{c}\text { Diagnosis } \dagger \\
\text { - Sepsis }\end{array}$ & $95(39.1 \%)$ \\
- Urosepsis & $19(07.8 \%)$ \\
$\bullet$ Oneumonia & $35(14.4 \%)$ \\
\hline $\begin{array}{l}\text { Vital Sign (Body Temperature) } * \\
\text { - Low } \\
\text { - Normal }\end{array}$ & $94(36.7 \%)$ \\
\hline High/Fever & $05(02.4 \%)$ \\
\hline Patient Intubated * & $191(91.0 \%)$ \\
- Nes & $14(06.7 \%)$ \\
\hline & $130(62.5 \%)$ \\
\hline MAP (mmHg) & $78(37.5 \%)$ \\
\hline Heart Rate & Mean \pm SD \\
\hline Respiratory Rate & $82.2 \pm 18.9$ \\
\hline
\end{tabular}

Note: *Missing cases were excluded from analysis.

Abbreviation: MAP, mean arterial pressure; Mean \pm SD, mean and standard deviation.

highest survival rates have been detected on $0-0.99$ $(68.8 \%)$ and $1-1.99(68.6 \%)$. On the characteristics of patients during initial ICU admission, the most common diagnosis infection during initial ICU admission was sepsis $(39.1 \%)$, followed by pneumonia $(16.5 \%)$ and the least of them was urosepsis $(7.8 \%)$. Nearly all of them have normal body temperature (90.5\%), 15 cases with high temperature and 5 cases with low temperature. We also detected a high proportion of patients being intubated (77.3\%) during initial ICU admission. Further laboratory characteristics of the 243 patients are detailed in Table 3.

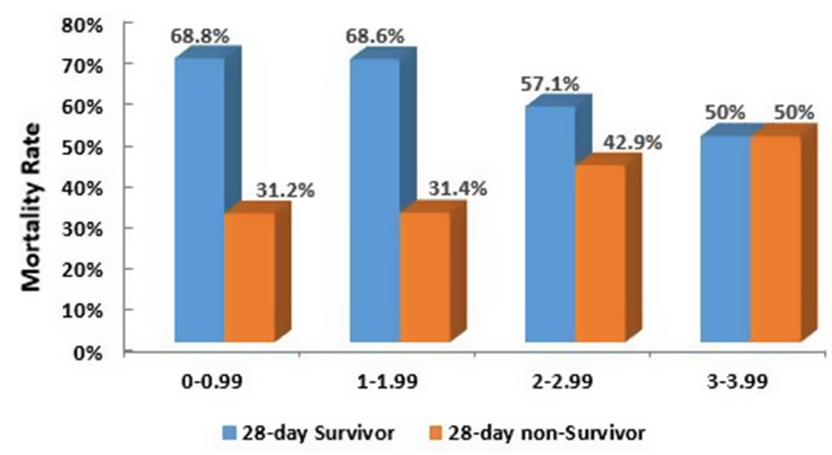

Figure I Mortality rate of patients whose initial norepinephrine administration were within the indicated time interval (hours). 
Table 3 Characteristics of Patients

\begin{tabular}{|c|c|}
\hline Characteristics & $\begin{array}{l}N(\%) \\
(n=243)\end{array}$ \\
\hline $\begin{array}{l}\text { Infection Diagnosis } \\
\text { - Sepsis } \\
\text { - Urosepsis } \\
\text { - Pneumonia } \\
\text { - Others }\end{array}$ & $\begin{array}{l}95(39.1 \%) \\
19(07.8 \%) \\
40(16.5 \%) \\
89(36.6 \%)\end{array}$ \\
\hline $\begin{array}{l}\text { Patient Intubated * } \\
\text { - Yes } \\
\text { - No }\end{array}$ & $\begin{array}{l}163(77.3 \%) \\
48(22.7 \%)\end{array}$ \\
\hline & Mean \pm SD \\
\hline MAP $(\mathrm{mmHg})$ & $80.6 \pm 17$ \\
\hline Vital Sign - Heart Rate & $97.9 \pm 24$ \\
\hline $\begin{array}{l}\text { ABG (Arterial Blood Gas) } \\
\text { - } \mathrm{PH} \\
\text { - } \mathrm{PCO} 2 \\
\text { - } \mathrm{PO} 2\end{array}$ & $\begin{array}{l}07.4 \pm 01.3 \\
37.5 \pm 13.9 \\
127.8 \pm 71.5\end{array}$ \\
\hline APACHE II Score & $16.9 \pm 08.3$ \\
\hline $\begin{array}{l}\text { Electrolytes } \\
\text { - Sodium }(\mathrm{Na}) \text { Level } \\
\text { - Potassium }(\mathrm{K}) \text { Level }\end{array}$ & $\begin{array}{l}\mid 40.6 \pm 17.7 \\
04.2 \pm 01.1\end{array}$ \\
\hline $\begin{array}{l}\text { Laboratory Results } \\
\text { - Hemoglobin } \\
\text { - Hematocrit } \\
\text { - WBC } \\
\text { - Platelet } \\
\text { - Prothrombin in time } \\
\text { - Creatinine (Serum) } \\
\text { - BUN } \\
\text { - Lactic Acid } \\
\text { - CRP }\end{array}$ & $\begin{array}{l}09.9 \pm 02.2 \\
30.8 \pm 06.7 \\
18.2 \pm 21.9 \\
218.7 \pm 135.8 \\
19.1 \pm 09.1 \\
02.3 \pm 02.4 \\
38.9 \pm 34.2 \\
04.8 \pm 05.5 \\
07.8 \pm 07.4\end{array}$ \\
\hline
\end{tabular}

Note: *Missing cases were excluded from analysis.

Abbreviation: MAP, mean arterial pressure; Mean \pm SD, mean and standard deviation.

\section{Mortality Rate and Clinical Characteristics of Patients}

When we compared the 28-day survivor and 28 days nonsurvivor patients among the clinical characteristics of patients during initial admission to ICU we found out that the survival rates of intubated patients are significantly less compared to those without intubation $(\mathrm{p}-<0.001)$. The mean differences of $\mathrm{pH}$ among 28-days survivor versus 28-day non-survivor were statistically significant $(\mathrm{p}-0.001)$ while the mean differences of PO2 between 28-day survivor versus 28-day non-survivor were found to be significant (p-0.010). When comparing the mean differences of APACHE II score between 28-survivor and 28-nonsurvivor, it was found the difference was significant ( $\mathrm{p}-<0.001$ ). Additionally, the mean differences of hemoglobin (p-0.018), hematocrit (p-0.015), lactic acid (p-0.044) and CRP (p-0.007) were all statistically significant (Table 4).

\section{Univariate Logistic Regression Analysis to Predict Survivor for Patients in ICU}

A univariate logistic regression analysis was performed to ascertain the effect of survival rate among selected clinical parameters. Regressors included in the model such as patients intubated, pH, PO2, APACHE II score, hemoglobin, hematocrit, lactic acid and CRP. It showed that the chances of non-survival rates were significantly higher in non-intubated patients than intubated patients. The odds ratio suggested that non-survival rate significantly increases more than 7 times in intubated patients than none-intubated patients $(\mathrm{OR}=7.049, \mathrm{p}-0.002)$. We also found out that a decrease in $\mathrm{pH}$ was significantly associated with an increase of non-survival rates $(\mathrm{OR}=0.013$, $\mathrm{p}-0.006)$ whereas, increased PO2 was associated with an increased survival rates $(\mathrm{OR}=1.005, \mathrm{p}-0.032)$. Moreover, an increased APACHE II score is likely to increase the chance of non-survival rate. When APACHE II score increases by one unit, then the chance of non-survival rate significantly increases with $14 \%$ approximately $(\mathrm{OR}=1.136$ 95\% CI $(1.070-1.206) \mathrm{P}$ value $=<0.001) . \mathrm{On}$ the other hand, a decreased of hemoglobin was associated with increased non-survival rates. Odds ratio suggested that increase in hemoglobin by one unit can reduce the non-survival rate by $17 \%(\mathrm{OR}=0.833, \mathrm{p}-0.028)$. Decreased hematocrit was associated with increased non-survival rate. The change of non-survival rate reduces by approximately $6 \%$ when hematocrit increases with one unit $(\mathrm{P}=0.029, \quad \mathrm{OR}=0.9421) . \quad$ This is identical CRP $(\mathrm{OR}=0.913, \mathrm{p}-0.011)$ (Table 5).

\section{Discussion}

From the results, early administration of norepinephrine led to an improvement in outcomes as indicated by survival rate growth in patients who were admitted in the ICU for both medical and surgical reasons for patients experiencing a septic shock. High mortality in the ICU units was observed when patients received their norepinephrine more than 2 hours after the admission to the intensive care unit. A previous study by Permpikul et al established 
Table 4 Relationship Between Mortality Rate and Clinical Characteristics of Patients During Initial ICU Admission ( $n=197)$

\begin{tabular}{|c|c|c|c|}
\hline Factor & $\begin{array}{l}\text { 28-Day Survivor } \\
\text { N (\%) } \\
(n=129)\end{array}$ & $\begin{array}{l}\text { 28-Day Non-Survivor } \\
\text { N (\%) } \\
(\mathrm{n}=68)\end{array}$ & P-value \\
\hline $\begin{array}{l}\text { First Administration of Norepinephrine }{ }^{\text {a }} \\
\text { - ER } \\
\text { - ICU }\end{array}$ & $\begin{array}{l}39(30.2 \%) \\
90(69.8 \%)\end{array}$ & $\begin{array}{l}26(38.2 \%) \\
42(61.8 \%)\end{array}$ & 0.256 \\
\hline $\begin{array}{l}\text { Patient Intubated }{ }^{\text {a }} \\
\text { - Yes } \\
\text { - No }\end{array}$ & $\begin{array}{l}82(70.7 \%) \\
34(29.3 \%)\end{array}$ & $\begin{array}{l}5 \mathrm{I}(94.4 \%) \\
03(05.6 \%)\end{array}$ & $<0.001 * *$ \\
\hline & Mean \pm SD & Mean \pm SD & \\
\hline Age in years ${ }^{b}$ & $59.9 \pm 21.3$ & $59.2 \pm 19.1$ & 0.855 \\
\hline $\operatorname{MAP}(\mathrm{mmHg})^{b}$ & $80.3 \pm 12.9$ & $77.6 \pm 22.2$ & 0.577 \\
\hline Heart Rate ${ }^{b}$ & $98.0 \pm 20.9$ & $100.0 \pm 32.2$ & 0.536 \\
\hline Respiratory Rate ${ }^{b}$ & $22.8 \pm 06.2$ & $22.7 \pm 05.3$ & 0.755 \\
\hline $\begin{array}{l}\text { ABG (Arterial Blood Gas) } \\
\text { - } \mathrm{PH} \\
\text { - } \mathrm{PCO} 2 \\
\text { - } \mathrm{PO} 2\end{array}$ & $\begin{array}{l}07.4 \pm 0.11 \\
37.6 \pm 11.6 \\
120.3 \pm 63.6\end{array}$ & $\begin{array}{l}07.3 \pm 0.11 \\
35.9 \pm 11.2 \\
148.3 \pm 87.6\end{array}$ & $\begin{array}{l}0.001 * * \\
0.309 \\
0.010 * *\end{array}$ \\
\hline APACHE II Score ${ }^{b}$ & $15.6 \pm 07.5$ & $23.0 \pm 07.6$ & $<0.001 * *$ \\
\hline $\begin{array}{l}\text { Electrolytes }^{b} \\
\text { - Sodium }(\mathrm{Na}) \text { Level } \\
\text { - Potassium (K) Level }\end{array}$ & $\begin{array}{l}143.2 \pm 06.7 \\
04.1 \pm 0.80\end{array}$ & $\begin{array}{l}\mid 37.3 \pm 25.7 \\
04.2 \pm 0 \mid .4\end{array}$ & $\begin{array}{l}0.130 \\
0.643\end{array}$ \\
\hline Time of Norepinephrine administration (h) ${ }^{b}$ & $0 \mathrm{I} .4 \pm 0 \mathrm{I} .6$ & $01.9 \pm 02.1$ & 0.053 \\
\hline $\begin{array}{l}\text { Laboratory Results }{ }^{\text {b }} \\
\text { - Hemoglobin } \\
\text { - Hematocrit } \\
\text { - WBC } \\
\text { - Platelet } \\
\text { - Prothrombin in time } \\
\text { - BUN } \\
\text { - Lactic Acid } \\
\text { - CRP }\end{array}$ & $\begin{array}{l}10.3 \pm 02.1 \\
31.7 \pm 06.6 \\
15.1 \pm 08.1 \\
227.5 \pm 152.2 \\
17.9 \pm 08.0 \\
02.1 \pm 01.9 \\
38.7 \pm 32.9 \\
03.9 \pm 04.7 \\
05.4 \pm 06.4\end{array}$ & $\begin{array}{l}09.4 \pm 02.4 \\
29.0 \pm 06.8 \\
22.9 \pm 32.8 \\
208.0 \pm 117.9 \\
20.2 \pm 09.4 \\
02.5 \pm 02.8 \\
35.9 \pm 34.9 \\
05.9 \pm 06.5 \\
09.8 \pm 07.7\end{array}$ & $\begin{array}{l}0.018 * * \\
0.015 * * \\
0.484 \\
0.656 \\
0.113 \\
0.544 \\
0.366 \\
0.044 * * \\
0.007 * *\end{array}$ \\
\hline
\end{tabular}

Notes: ${ }^{\mathrm{a}} \mathrm{P}$-value has been calculated using chi-square test. ${ }^{\mathrm{b}} \mathrm{P}$-value has been calculated using Mann Whitney $U$-test. **Significant at $\mathrm{p} \leq 0.05$ level.

Abbreviation: MAP, mean arterial pressure.

that early norepinephrine administration resulted in more effective outcomes characterized by high survival rates and reduction in mortality for patients in the emergency department. $^{6}$ The current study found that the highest survival rate was during $0-0.99$ hours at $68.8 \%$ and $1-1.99$ hours at $68.6 \%$. These findings revealed that the early administration of norepinephrine for patients' inhospital gave the best outcomes in terms of reducing the mortality rate and increasing survival rate. This study established the effectiveness of norepinephrine for patients with sepsis and septic shock under intensive care. This multi-ICU unit study used in this research provided clear outcomes on the value of early norepinephrine administration for the treatment of septic shock patients under intensive care.

Similar findings were identified in Rahnema and Jones study that reported effectiveness in the early intervention of septic shock to patients within the emergency 
Table 5 Univariate Logistic Regression Analysis to Predict NonSurvivor from the Clinical Characteristics of Patients During Initial Admission to ICU $(n=197)$

\begin{tabular}{|c|c|c|c|}
\hline Factor & Odds Ratio & $95 \% \mathrm{Cl}$ & P-value \\
\hline $\begin{array}{l}\text { Patient intubated } \\
\text { - Yes } \\
\text { - No }\end{array}$ & $\begin{array}{l}\text { Ref } \\
7.049\end{array}$ & $2.058-24.142$ & $0.002 * *$ \\
\hline $\mathrm{pH}$ & 0.013 & $0.001-0.287$ & $0.006 * *$ \\
\hline $\mathrm{PO}_{2}$ & 1.005 & $1.000-1.010$ & $0.032 * *$ \\
\hline APACHE II Score & 1.136 & $1.070-1.206$ & $<0.001 * *$ \\
\hline Hemoglobin & 0.833 & $0.708-0.980$ & $0.028 * *$ \\
\hline Hematocrit & $0.94 I$ & $0.891-0.994$ & $0.029 * *$ \\
\hline Lactic Acid & 1.070 & $0.997-1.148$ & 0.060 \\
\hline
\end{tabular}

Note: **Significant at $p \leq 0.05$ level.

Abbreviation: $\mathrm{Cl}$, confidence interval.

department under norepinephrine. ${ }^{1}$ Previous studies found high effectiveness in the early administration of norepinephrine, which improved the outcomes of patients through increased survival rates and a decrease in the mortality rate when norepinephrine was administered during the first hours of intensive care. ${ }^{2,3}$ Furthermore, the current study reported increased mortality when an hourly delay in the administration of norepinephrine was reported, which conforms to the previous findings. In the retrospective study using a large dataset, the results indicated that delays in the administration of norepinephrine for patients in intensive care unit due to septic shock was associated with a higher rate of mortality. ${ }^{13}$ In similar findings, Levy et al identified that delayed administration resulted to increase in in-hospital mortality with a linear increase in the risk of mortality for each time of delay in norepinephrine administration. ${ }^{10}$ Similar findings were identified in the current study, which found highest survival rates when the norepinephrine for treatment of the septic shock was provided in the first hours of admission in the intensive care unit and reduction in case fatality rates. ${ }^{10}$ These studies associated early norepinephrine administration with a low mortality rate and increased survival rates.

Ideally, similar linear findings were observed in the current study where linear delay in increased mortality rate in all the observational studies reviewed. ${ }^{1,13,14}$ Watkins et al. further demonstrated that improvement in outcomes through early norepinephrine intervention in triage time or qualification of early goal-oriented therapy was appropriate within the first three hours resulting in high rates of survival and reduced rates of mortality. ${ }^{5}$ Other studies have also identified deterioration in patients' outcomes and increased mortality for the length of stay, lung injury, kidney failure, and organ failure due to delay in initiation of the norepinephrine intervention. ${ }^{11,13,14}$ In a larger multicenter study, hourly delay in the initiation of the norepinephrine intervention was linked to increasing in-facility mortality from the enrollment of the population based on a random sample that used disease code. ${ }^{13}$ However, a meta-analysis did not report the benefit of immediate norepinephrine use for patients with septic shock due to criticism over heterogeneity of the studies included and limited use of norepinephrine with appropriate microbial capabilities. ${ }^{13,14}$ Permpikul et al further identified the link between time and initiation of norepinephrine administration on clinical outcomes for patients with severe sepsis. ${ }^{6}$ Similar to the current study, previous studies have collectively associated early initiation of norepinephrine administration with increased survival rates and reduction in the mortality rates for sepsis and septic shock. ${ }^{1,3,8,12}$ The outcomes were more positive whether the intervention for norepinephrine administration was provided in the first hours of the admission in the emergency department or the intensive care units.

The current study provides critical relationships between early norepinephrine on survival rate and mortality rates. Ability to compare survival and mortality rates for different times enabled this research to determine that early norepinephrine administration could help in reducing mortality rate and increasing survival rate. The findings of the current study are highly applicable in the development of evidence-based clinical guidelines on measures to reduce mortality rate and increase survival rate as the main goal of providers in the intensive care setting. The study has demonstrated that early norepinephrine administration could help save lives from sepsis and septic shock when intervention is provided with three hours of admission in ICU. However, the study presents several important limitations. First, the study design involved a retrospective observational study that limits understanding of the precise relationship between the administration of norepinephrine in time intervals and impacts on survival and mortality rates in the intensive care setting. Additionally, the study used a small sample size that affects the ability to generalize the study in the entire population. Also 46 cases we were missing 
their final outcome (mortality) and thus could've affect the final outcome results. Also there was no data collected on fluid management which could've effect the overall outcome since under or over fluid resuscitation may have a negative impact on the outcome. Therefore, a larger multicenter cohort is recommended in future to validate whether early norepinephrine administration could decrease the mortality rate associated with septic shock in patients within the intensive care setting.

\section{Conclusions}

The study aimed at evaluating the association between early administration of norepinephrine in septic shock and survival rate using a retrospective single-center observational study in a sample drawn from the Kingdom of Saudi Arabia. Findings identify that early norepinephrine administration was linked to a reduction in mortality rate and improvement in survival rate for patients in intensive care units for the treatment of sepsis and septic shock. When the administration of norepinephrine was delayed, there was an increase in mortality rate and decreased the survival rate of patients. Therefore, early intervention for norepinephrine administration to treat sepsis and septic shock in admitted patients may improve the survival rate of patients and reduce mortality in the intensive care units.

\section{Data Sharing Statement}

All de-identified data used in this study are available from the corresponding author upon reasonable request.

\section{Author Contributions}

All authors MA, RA contributed to data analysis, writing and revising the article, have agreed on the Open Access Emergency Medicine Journal for article submission. All authors approved the final version of the manuscript to be published and agreed to be accountable for all aspects of the work.

\section{Funding}

This research received no external funding.

\section{Disclosure}

The authors declare that they have no competing interests.

\section{References}

1. Rahnema A, Jones J. Early use of norepinephrine in septic shock resuscitation (CENSER): a randomized trial. J Emerg Med. 2019;56 (6):729-730. doi:10.1016/j.jemermed.2019.05.004

2. Russell J, Lee T, Singer J, De Backer D, Annane D. Days alive and free as an alternative to a mortality outcome in pivotal vasopressor and septic shock trials. J Crit Care. 2018;47:333-337. doi:10.1016/j. jcrc.2018.05.003

3. Maheshwari K, Nathanson B, Munson S, et al. The relationship between ICU hypotension and in-hospital mortality and morbidity in septic patients. Intensive Care Med. 2018;44(6):857-867. doi:10.1007/s00134-018-5218-5

4. Rowan K, Angus D, Bailey M, Barnato A. Early, goal-directed therapy for septic shock-a patient-level meta-analysis. $N$ Engl $J$ Med. 2017;376(23):2223-2234.

5. Watkins R, Haller N, Wayde M, Armitage K. A multicenter survey of house staff knowledge about sepsis and the "surviving sepsis campaign guidelines for management of severe sepsis and septic shock". $J$ Intensive Care Med. 2017;35(2):187-190. doi:10.1177/ 0885066617737304

6. Permpikul C, Tongyoo S, Viarasilpa T, Trainarongsakul T, Chakorn T, Udompanturak S. Early use of norepinephrine in septic shock resuscitation (CENSER). A randomized trial. Am J Respir Crit Care Med. 2019;199(9):1097-1105. doi:10.1164/rccm.2018061034OC

7. Vail E, Gershengorn H, Hua M, Walkey A, Rubenfeld G, Wunsch H. Association between US norepinephrine shortage and mortality among patients with septic shock. JAMA. 2017;317(14):1433. doi:10.1001/jama.2017.2841

8. Ospina-Tascón G, Hernandez G, Alvarez I, et al. Effects of very early start of norepinephrine in patients with septic shock: a propensity score-based analysis. Critical Care. 2020;24(1):1-11. doi:10.1186/ s13054-020-2756-3

9. Levy M, Dellinger R, Townsend S, et al. The Surviving Sepsis Campaign: results of an international guideline-based performance improvement program targeting severe sepsis*. Crit Care Med. 2010;38(2):367-374. doi:10.1097/CCM.0b013e3181cb0cdc

10. Levy M, Rhodes A, Phillips G, et al. Surviving Sepsis Campaign: association between performance metrics and outcomes in a 7.5-year study. Intensive Care Med. 2014;40(11):1623-1633. doi:10.1007/ s00134-014-3496-0

11. Zanotti-Cavazzoni S. Vasopressin or norepinephrine in early hyperdynamic septic shock: a randomized clinical trial. Yearbook Crit Care Med. 2008;2008:168-170. doi:10.1016/S0734-3299(08)70552-5

12. Comstock G. Time to treatment and mortality during mandated emergency care for sepsis. J Emerg Med. 2017;53(4):602-603. doi:10.1016/j.jemermed.2017.08.088

13. Hamzaoui O, Jozwiak M, Geffriaud T, et al. Norepinephrine exerts an inotropic effect during the early phase of human septic shock. $\mathrm{Br}$ $J$ Anaesth. 2018;120(3):517-524. doi:10.1016/j.bja.2017.11.065

14. Spoelstra - de Man A, Girbes A. Comment on "Surviving Sepsis Campaign: international guidelines for management of severe sepsis

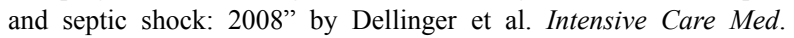
2008;34(6):1160-1162. doi:10.1007/s00134-008-1089-5

15. Bai X, Yu W, Ji W, et al. Early versus delayed administration of norepinephrine in patients with septic shock. Critical Care. 2014;18 (5):532. doi:10.1186/s13054-014-0532-y 


\section{Publish your work in this journal}

The Open Access Emergency Medicine is an international, peerreviewed, open access journal publishing original research, reports, editorials, reviews and commentaries on all aspects of emergency medicine. The manuscript management system is completely online

and includes a very quick and fair peer-review system, which is all easy to use. Visit http://www.dovepress.com/testimonials.php to read real quotes from published authors.

Submit your manuscript here: https://www.dovepress.com/open-access-emergency-medicine-journal 